\title{
Predictive factors for breast cancer in patients diagnosed atypical ductal hyperplasia at core needle biopsy Byung Joo Chae ${ }^{1,3}$, Ahwon Lee ${ }^{2,3}$, Byung Joo Song*1,3 and Sang Seol Jung1,3
}

\author{
Address: ${ }^{1}$ Department of Surgery, Catholic University of Korea, Seoul, Korea, ${ }^{2}$ Department of Pathology, Catholic University of Korea, Seoul, Korea \\ and ${ }^{3}$ Breast Center Multidisciplinary Team, Department of Surgery, Seoul St Mary's Hospital, Seoul, Korea \\ Email: Byung Joo Chae - bjchae@gmail.com; Ahwon Lee - klee@catholic.ac.kr; Byung Joo Song* - byungjoo.song@gmail.com; \\ Sang Seol Jung - ssjung@catholic.ac.kr \\ * Corresponding author
}

Published: 23 October 2009

World Journal of Surgical Oncology 2009, 7:77 doi:10.1 186/1477-7819-7-77

This article is available from: http://www.wjso.com/content/7/I/77

(C) 2009 Chae et al; licensee BioMed Central Ltd.

This is an Open Access article distributed under the terms of the Creative Commons Attribution License (http://creativecommons.org/licenses/by/2.0), which permits unrestricted use, distribution, and reproduction in any medium, provided the original work is properly cited.
Received: 5 July 2009

Accepted: 23 October 2009

\begin{abstract}
Background: Percutaneous core needle biopsy (CNB) is considered to be the standard technique for histological diagnosis of breast lesions. But, it is less reliable for diagnosing atypical ductal hyperplasia (ADH). The purpose of the present study was to predict, based on clinical and radiological findings, which cases of ADH diagnosed by CNB would be more likely to be associated with a more advanced lesion on subsequent surgical excision.
\end{abstract}

Methods: Between February 2002 and December 2007, consecutive ultrasound-guided CNBs were performed on suspicious breast lesions at Seoul St. Mary's Hospital. A total of 69 CNBs led to a diagnosis of $A D H$, and 45 patients underwent follow-up surgical excision. We reviewed the medical records and analyses retrospectively.

Results: Sixty-nine patients were diagnosed with ADH at CNB. Of these patients, 45 underwent surgical excision and $10(22.2 \%)$ were subsequently diagnosed with a malignancy (ductal carcinoma in situ, $n=8$; invasive cancer, $n=2)$. Univariate analysis revealed age ( $\geq 50$-years) at the time of core needle biopsy $(p=0.006)$, size $(>10 \mathrm{~mm})$ on imaging $(p=0.033)$, and combined mass with microcalcification on sonography $(p=0.029)$ to be associated with underestimation. When those three factors were included in multivariate analysis, only age $(p=0.035$, HR $6.201,95 \% \mathrm{Cl}$ I.13533.891) was an independent predictor of malignancy.

Conclusion: Age $(\geq 50)$ at the time of biopsy is an independent predictive factor for breast cancer at surgical excision in patients with diagnosed $A D H$ at CNB. For patients diagnosed with ADH at $\mathrm{CNB}$, only complete surgical excision is the suitable treatment option, because we could not find any combination of factors that can safely predict the absence of DCIS or invasive cancer in a case of $\mathrm{ADH}$.

\section{Background}

Percutaneous core needle biopsy (CNB) is the standard technique for histological diagnosis of breast lesions. It has become the procedure of choice to investigate suspicious lesions of the breast and has been shown to be an effective means to rule out cancer, alleviating the cost and discomfort of surgery. Overall, CNB histological findings are in agreement with surgical biopsy in more than 95\% of the cases [1-3]. But, CNB is less reliable for diagnosing atypical ductal hyperplasia (ADH). 
$\mathrm{ADH}$ is a proliferative lesion of the breast epithelium, which fulfils some but not all the criteria of low grade ductal carcinoma in situ (DCIS) [4]. ADH carries a 4-5 times increased risk of subsequent development of invasive carcinoma in either breast, $[5,6]$ and there is genetic evidence in cell populations associated with cancer suggesting it may even be a direct precursor of malignancy[7]. Significant discordance has been reported isn CNB diagnosis of $\mathrm{ADH}$, with $7 \%-87 \%$ of cases proving to be DCIS or invasive carcinoma on subsequent surgical excision [8-14]. This problem arises from the difficulty in differentiating between ADH and low grade DCIS on the small volume of tissue obtained from core biopsy [15]. In addition, foci of ADH may be present at the periphery of areas of DCIS [16] and, thus, even an unequivocal diagnosis of ADH does not preclude the presence of an adjacent and more advanced lesion. Because of this underestimation (which means presence of DCIS or invasive cancer) risk, some authors have recommended a mandatory surgical biopsy, while others have discussed options between surgery and follow-up [17]. Identification of patients with ADH diagnosed by CNB who can be spared surgical excision is an area of active investigation. However, the clinical, radiologic, and pathologic parameters on which to base this decision have not been consistently identified.

The purpose of the present study was to predict, based on clinical and radiological findings, which cases of ADH diagnosed by CNB would be more likely to be associated with a more advanced lesion on subsequent surgical excision.

\section{Materials and methods}

Between February 2002 and December 2007, 3476 consecutive ultrasound-guided CNBs were performed on suspicious breast lesions at the Seoul St. Mary's Hospital. A total of $69 \mathrm{CNBs}$ led to a diagnosis of $\mathrm{ADH}$, and 45 patients underwent follow-up surgical excision. Seven patients refused surgical excision and were only followed up and 12 patients were transferred other hospital as per their request while 5 were lost to follow-up. The definition employed for "histological underestimation" was a lesion diagnosed as $\mathrm{ADH}$ at $\mathrm{CNB}$ that was revealed to harbor malignant foci at follow-up surgical excision, including DCIS and invasive cancer. All patients in this study underwent clinical and radiological examination, including mammography and ultrasound. The radiological appearance of the lesion was characterized according to the American College of Radiology Breast Imaging Reporting and Data System lexicon and the final assessment categories. All lesions were evaluated for size on imaging and presence of microcalcification. Lesion size was defined as the greatest dimension on ultrasound imaging for most patients, or mammography size for patients with microcalcification dominant lesions. Ultrasound-guided biop- sies were used for sonographically visible lesions, and were performed with patients in a supine or decubitus position using high-resolution sonography. The biopsy was performed using a device with a 14-gauge automated needle or with an 11-gauge vacuum assisted biopsy device. The core biopsy tissue sections were fixed in $10 \%$ formaldehyde and embedded in paraffin. Each biopsy specimen was stained with hematoxylin and eosin. The biopsy slides were reviewed by experienced pathologists and diagnosed according to the ADH diagnostic criteria of the World Health Organization guidelines. The data were analyzed using Chi-square and logistic regression, as well as Fisher exact test for the small sample. $P$ values $<0.05$ were considered statistically significant.

\section{Results}

Sixty-nine patients were diagnosed with ADH at CNB. Of these, 45 underwent surgical excision at our institution. Of the 45 patients, $10(22.2 \%)$ were diagnosed with a malignancy after surgical excision (DCIS, $\mathrm{n}=8$; invasive cancer, $\mathrm{n}=2$ ). Table 1 summarizes the underestimation rates and distribution in all patients according to clinical, radiological, and pathological variables, and compares the accurate diagnoses $(n=35)$ and underestimations ( $n$ $=10$ ) according to patient, lesion, and biopsy variables. Six (13.3\%) underwent 11-gauge stereotactic vacuum assisted biopsy because lesions were seen mainly by mammography rather than ultrasound. Women in the accurate diagnosis group were younger than those in the underestimation group $(p=0.003)$. Nine of the 39 ADH lesions $(23.1 \%)$ found with 14-gauge automated gun biopsies were upgraded to carcinoma, and one of the six ADH lesions $(16.7 \%)$ found with 11-gauge vacuum-assisted biopsies were upgraded to carcinoma. The underestimation rate for the 11-gauge vacuum-assisted biopsy $(16.7 \%)$ was not significantly lower than that for the 14 gauge automated gun biopsy $(23.1 \%)(\mathrm{p}=0.725)$.

Univariate analysis revealed that age ( $\geq 50$ years) at the time of core needle biopsy ( $\mathrm{p}=0.006)$, size on imaging ( $>$ $10 \mathrm{~mm} ; \mathrm{p}=0.033$ ), and combined mass with microcalcification on sonography ( $\mathrm{p}=0.029)$ were associated with underestimation (Table 2). When those three factors were included in multivariate analysis, only age at the time of core needle biopsy ( $\mathrm{p}=0.035$, HR 6.201, 95\% CI 1.13533.891) was found to be an independent predictor of malignancy, whereas size on imaging and combined mass with microcalcification on sonography were negative predictors. (Table 3)

\section{Discussion}

In the present study, clinico-pathological and radiological findings of $\mathrm{ADH}$ diagnosed by $\mathrm{CNB}$ were assessed to clarify predictors that could be useful in distinguishing between $\mathrm{ADH}$ and cancer containing DCIS. ADH is a bor- 
Table I: Pathologic results after surgical excision according to clinical, radiological and histological variables.

\begin{tabular}{|c|c|c|c|c|c|}
\hline & & \multicolumn{2}{|c|}{ Pathology after excision } & \multirow{2}{*}{$\begin{array}{l}\text { Underestimation } \\
\text { rate }(22.2 \%)\end{array}$} & \multirow{2}{*}{$\begin{array}{c}\text { P value } \\
\text { (Chi-square) }\end{array}$} \\
\hline & & Benign $(n=35)$ & Malignancy $(n=10)$ & & \\
\hline \multirow[t]{2}{*}{ Age (years) } & $<50$ & $28(80 \%)$ & $3(30 \%)$ & $9.7 \%$ & $\underline{0.003}$ \\
\hline & $\geq 50$ & $7(20 \%)$ & 7 (70\%) & $50 \%$ & \\
\hline \multirow[t]{2}{*}{ Mass on MMG } & Yes & $10(32.3 \%)$ & $4(50 \%)$ & $28.6 \%$ & 0.351 \\
\hline & No & $21(67.7 \%)$ & $4(50 \%)$ & $16 \%$ & \\
\hline \multirow[t]{2}{*}{ MIC on MMG } & Yes & $8(25.8 \%)$ & $4(50 \%)$ & $33.3 \%$ & 0.186 \\
\hline & No & $23(74.2 \%)$ & $4(50 \%)$ & $14.8 \%$ & \\
\hline \multirow[t]{2}{*}{ Mass + MIC on MMG } & Yes & I (3.I\%) & $2(22.2 \%)$ & $66.7 \%$ & 0.52 \\
\hline & No & 31 (96.9\%) & 7 (77.8\%) & $18.4 \%$ & \\
\hline \multirow[t]{2}{*}{ Lesion size } & $\leq \mathrm{l} \mathrm{cm}$ & $23(69.7 \%)$ & $3(30 \%)$ & $11.5 \%$ & 0.024 \\
\hline & $>1 \mathrm{~cm}$ & $10(30.3 \%)$ & 7 (70\%) & $41.2 \%$ & \\
\hline \multirow{2}{*}{ Mass on USG } & Yes & 27 (77.1\%) & $9(90 \%)$ & $25 \%$ & 0.370 \\
\hline & No & $8(22.9 \%)$ & $\mathrm{I}(0 \%)$ & $11.1 \%$ & \\
\hline \multirow[t]{2}{*}{ MIC USG } & Yes & $2(5.7 \%)$ & $3(30 \%)$ & $60 \%$ & $\underline{0.031}$ \\
\hline & No & $33(94.3 \%)$ & 7 (70\%) & $17.5 \%$ & \\
\hline \multirow[t]{2}{*}{ Mass + MIC on USG } & Yes & I (2.9\%) & $3(30 \%)$ & $75 \%$ & $\underline{0.008}$ \\
\hline & No & 34 (97.I\%) & 7 (70\%) & $17.1 \%$ & \\
\hline \multirow[t]{2}{*}{ Needle size } & I4 Gauge & 30 (85.7\%) & $9(90 \%)$ & $23.1 \%$ & 0.725 \\
\hline & II Gauge & $5(14.3 \%)$ & I $(0 \%)$ & $16.7 \%$ & \\
\hline \multirow[t]{2}{*}{ Number of Cores } & $\leq 5$ & 30 (85.7\%) & $8(80 \%)$ & $21.1 \%$ & 0.660 \\
\hline & $>5$ & $5(14.3 \%)$ & $2(20 \%)$ & $28.6 \%$ & \\
\hline
\end{tabular}

MMG: mammogram, MIC: microcalcification, USG: ultrasonography

Table 2: Results of univariate analysis

\begin{tabular}{lccc}
\hline & HR & $\mathbf{9 5 \%} \mathbf{C l}$ & P-value \\
\hline Age & 9.333 & $1.911-45.583$ & $\underline{\mathbf{0 . 0 0 6}}$ \\
Mass MMG & 2.1 & $0.434-10.168$ & 0.357 \\
MIC MMG & 2.875 & $0.579-14.275$ & 0.196 \\
Mass + MIC MMG & 8.857 & $0.701-111.937$ & 0.092 \\
Lesion size & 5.367 & $1.147-25.105$ & $\underline{\mathbf{0 . 0 3 3}}$ \\
Mass USG & 2.667 & $0.292-24.345$ & 0.385 \\
MIC USG & 4.571 & $0.758-27.577$ & 0.097 \\
Mass + MIC USG & 14.571 & $1.315-161.418$ & $\underline{\mathbf{0 . 0 2 9}}$ \\
Needle size & 1.50 & $0.155-14.557$ & 0.727 \\
Number of cores & 1.50 & $0.244-9.219$ & 0.662 \\
\hline
\end{tabular}

HR: hazard ratio; Cl: confidence interval; MMG: mammogram; MIC: microcalcification; USG: ultrasonography
Table 3: Results of Multivariate analysis.

\begin{tabular}{lccc}
\hline & HR & 95\% Cl & P-value \\
\hline Age & 6.201 & $1.135-33.891$ & 0.035 \\
Lesion size & 2.878 & $0.474-17.465$ & 0.250 \\
Mass + MIC USG & 4.571 & $0.288-72.609$ & 0.281
\end{tabular}

HR: hazard ratio; Cl: confidence interval; MMG: mammogram; MIC: microcalcification; USG: ultrasonography 
derline lesion on histology that is difficult to distinguish from low grade DCIS on the small tissue sample provided by CNB. Because of this difficulty, clinico-pathologic and radiologic findings that can help discriminate between $\mathrm{ADH}$ and DCIS are valuable in planning patient management.

Although some variables like lesion size, combined mass, and microcalcification on sonography also tended to increased underestimation, only age at the time of biopsy ( $\geq 50$ years) was presently determined to be an independent predictive factor for breast cancer at surgical excision in patients with diagnosed ADH at CNB. Consistent with our findings, Ko et al [18] observed an increase in underestimation rates in subjects aged 50 years and older, microcalcification on mammography and, lesion size > $15 \mathrm{~mm}$.

Several studies have examined various mammographic, clinical, and pathological factors that may predict the presence of a more significant lesion on surgical excision after a CNB diagnosis of ADH [12,19-21]. It is believed that the variability of cancer rates depends on the size and features of the mammographic lesion, size of the biopsy needle, extent and completeness of sampling of the mammographic target lesion, histological criteria used to diagnose ADH versus DCIS and/or usual hyperplasia, and the threshold for surgical excision.

Use of vacuum assistance and more extensive sampling have improved the underestimation of carcinoma on surgical biopsy after a diagnosis of ADH on CNB from 33\%$48 \%[2,21]$ to $7 \%-35 \%[14,22-25]$. Although reduced underestimation with use of an 11-gauge vacuum-assisted device is explained by larger sample volumes, the number of specimens obtained presently appeared not to be correlated with a lower rate of underestimation. These results are similar to those of a previous study [12], in which the investigators found that specimen numbers per lesion did not correlate with underestimation, but that complete lesion removal did correlate with degree of underestimation. These findings indicate that targeting precision is more important than sample numbers. Further studies with more cases are needed to determine whether complete lesion removal at sonographically guided 11-gauge vacuum-assisted biopsy can reduce the rate of underestimation of ADH.

Jackman et al, [26] recognized that as the maximum diameter of the mammographic lesion increased, so does the rate of $\mathrm{ADH}$ underestimation. Also, in the present study, lesion size on imaging of $>1 \mathrm{~cm}$ increased underestimation rates. However, lesion size was not an independent predictor upon multivariate analysis.
Microcalcification with or without a mass has been reported to be the most common finding for both $\mathrm{ADH}$ (58\% 88\%) and DCIS (68\% 98\%) [8,27-29]. On histological examination, Helvie et al [10] found that the calcifications in mammary ducts within areas of $\mathrm{ADH}$, without cell necrosis. In DCIS, the calcifications develop in secretions and are dystrophic calcifications secondary to necrotic tumor cells [30,31]. These histological differences could potentially be associated with different mammographic findings. But, those detailed variables were not addressed in the present study. Presently, only the combined sonographic finding of mass and microcalcifications was a significant predictive factor for underestimation in the univariate analysis. It has been suggested that microcalcification on mammography is an independent predictor of malignancy at follow-up surgical excision in patients diagnosed with ADH at CNB [18]. Our results did not reveal statistical significance in this regard.

Limitations of the present study include its retrospective nature and that it did not involve a randomized series of patients. Furthermore, 24 (34.8\%) of the 69 ADH cases did not undergo surgical excision and were therefore excluded. It is possible that cases with a lower possibility of malignancy were recommended for imaging follow-up rather than surgical excision, which could affect the underestimation rate and other results.

\section{Conclusion}

Only age at the time of biopsy ( $\geq 50$ years) is an independent predictive factor for breast cancer at surgical excision in patients with diagnosed $\mathrm{ADH}$ at $\mathrm{CNB}$. Identification of patients with ADH diagnosed by $\mathrm{CNB}$ who can be spared surgical excision is an area of active investigation. However, at present, clinical, radiologic, and pathologic factors on which to base this decision have not been consistently identified. So, for patients diagnosed with $\mathrm{ADH}$ at $\mathrm{CNB}$, only complete surgical excision is a suitable treatment option because we could not find any combination of factors that can safely predict the absence of DCIS or invasive cancer in a case of ADH.

\section{Competing interests}

The authors declare that they have no competing interests.

\section{Authors' contributions}

BJC carried out the statistical analysis, participated in the sequence alignment and drafted and described the manuscript. AL carried out the Pathologic diagnosis. BJS and SSJ conceived of the study, and participated in its design and coordination and helped to draft the manuscript. All authors read and approved the final manuscript. 


\section{Acknowledgements}

This manuscript was supported by a grant from Gangneung Dong-In Hospital.

\section{References}

I. Dahlstrom JE, Sutton S, Jain S: Histological precision of stereotactic core biopsy in diagnosis of malignant and premalignant breast lesions. Histopathology 1996, 28:537-54I.

2. Jackman RJ, Nowels KW, Shepard MJ, Finkelstein SI, Marzoni FA Jr: Stereotaxic large-core needle biopsy of 450 nonpalpable breast lesions with surgical correlation in lesions with cancer or atypical hyperplasia. Radiology 1994, 193:91-95.

3. Parker SH, Lovin JD, Jobe WE, Burke BJ, Hopper KD, Yakes WF: Nonpalpable breast lesions: stereotactic automated largecore biopsies. Radiology 199|, 180:403-407.

4. Page DL, Dupont WD, Rogers LW, Rados MS: Atypical hyperplastic lesions of the female breast. A long-term follow-up study. Cancer 1985, 55:2698-2708.

5. Dupont WD, Page DL: Risk factors for breast cancer in women with proliferative breast disease. New England Journal of Medicine, The 1985, 3 | 2: |46-|5|.

6. Rosen PP: Proliferative breast "disease". An unresolved diagnostic dilemma. Cancer 1993, 71:3798-3807.

7. Shackney SE, Silverman JF: Molecular evolutionary patterns in breast cancer. Advances in anatomic pathology 2003, 10:278-290.

8. Liberman L, Cohen MA, Dershaw DD, Abramson AF, Hann LE, Rosen PP: Atypical ductal hyperplasia diagnosed at stereotaxic core biopsy of breast lesions: an indication for surgical biopsy. AJR Am J Roentgenol 1995, 164: I I I I-I I I3.

9. Renshaw AA, Cartagena N, Schenkman RH, Derhagopian RP, Gould EW: Atypical ductal hyperplasia in breast core needle biopsies. Correlation of size of the lesion, complete removal of the lesion, and the incidence of carcinoma in follow-up biopsies. Am J Clin Pathol 200I, I I6:92-96.

10. Harvey JM, Sterrett GF, Frost FA: Atypical ductal hyperplasia and atypia of uncertain significance in core biopsies from mammographically detected lesions: correlation with excision diagnosis. Pathology 2002, 34:410-416.

II. Bonnett M, Wallis T, Rossmann M, Pernick NL, Bouwman D, Carolin KA, Visscher D: Histopathologic analysis of atypical lesions in image-guided core breast biopsies. Mod Pathol 2003, 16:154-160

12. Jackman RJ, Birdwell RL, Ikeda DM: Atypical ductal hyperplasia: can some lesions be defined as probably benign after stereotactic I I-gauge vacuum-assisted biopsy, eliminating the recommendation for surgical excision? Radiology 2002, 224:548-554.

13. Ely KA, Carter BA, Jensen RA, Simpson JF, Page DL: Core biopsy of the breast with atypical ductal hyperplasia: a probabilistic approach to reporting. Am J Surg Pathol 200I, 25:1017-102I.

14. Sneige N, Lim SC, Whitman GJ, Krishnamurthy S, Sahin AA, Smith TL, Stelling CB: Atypical ductal hyperplasia diagnosis by directional vacuum-assisted stereotactic biopsy of breast microcalcifications. Considerations for surgical excision. American journal of clinical pathology 2003, I 1 9:248-253.

15. Darling ML, Smith DN, Lester SC, Kaelin C, Selland DL, Denison CM, DiPiro PJ, Rose DI, Rhei E, Meyer JE: Atypical ductal hyperplasia and ductal carcinoma in situ as revealed by large-core needle breast biopsy: results of surgical excision. AJR Am J Roentgenol 2000, 175: $134 \mid-1346$

16. Lennington WJ, Jensen RA, Dalton LW, Page DL: Ductal carcinoma in situ of the breast. Heterogeneity of individual lesions. Cancer 1994, 73: | | 8-124.

17. Forgeard C, Benchaib M, Guerin N, Thiesse P, Mignotte H, Faure C, Clement-Chassagne $C$, Treilleux I: Is surgical biopsy mandatory in case of atypical ductal hyperplasia on II-gauge core needle biopsy? A retrospective study of $\mathbf{3 0 0}$ patients. Am J Surg 2008, 196:339-345

18. Ko E, Han W, Lee JW, Cho J, Kim EK, Jung SY, Kang MJ, Moon WK, Park IA, Kim SW, et al: Scoring system for predicting malignancy in patients diagnosed with atypical ductal hyperplasia at ultrasound-guided core needle biopsy. Breast Cancer Res Treat 2008, I I 2:189-195.

19. Brown TA, Wall JW, Christensen ED, Smith DV, Holt CA, Carter PL, Patience TH, Babu SS, Williard WC: Atypical hyperplasia in the era of stereotactic core needle biopsy. I Surg Oncol 1998, 67:168-173.

20. Hoang JK, Hill P, Cawson JN: Can mammographic findings help discriminate between atypical ductal hyperplasia and ductal carcinoma in situ after needle core biopsy? Breast 2008, I7:282-288.

2I. Moore MM, Hargett CW 3rd, Hanks JB, Fajardo LL, Harvey JA, Frierson HF Jr, Slingluff CL Jr: Association of breast cancer with the finding of atypical ductal hyperplasia at core breast biopsy. Ann Surg 1997, 225:726-73I. discussion 73|-723.

22. Philpotts LE, Lee CH, Horvath LJ, Lange RC, Carter D, Tocino I: Underestimation of breast cancer with II-gauge vacuum suction biopsy. AJR Am J Roentgenol 2000, 175:1047-1050.

23. Adrales G, Turk P, Wallace T, Bird R, Norton HJ, Greene F: Is surgical excision necessary for atypical ductal hyperplasia of the breast diagnosed by Mammotome? Am J Surg 2000, 180:313-315.

24. Rao A, Parker S, Ratzer E, Stephens J, Fenoglio M: Atypical ductal hyperplasia of the breast diagnosed by I I-gauge directional vacuum-assisted biopsy. Am J Surg 2002, 184:534-537. discussion 537.

25. Burak WE Jr, Owens KE, Tighe MB, Kemp L, Dinges SA, Hitchcock $\mathrm{CL}$, Olsen J: Vacuum-assisted stereotactic breast biopsy: histologic underestimation of malignant lesions. Arch Surg 2000, 135:700-703.

26. Jackman RJ, Burbank F, Parker SH, Evans WP 3rd, Lechner MC, Richardson TR, Tocino I, Wray AB: Atypical ductal hyperplasia diagnosed at stereotactic breast biopsy: improved reliability with I4-gauge, directional, vacuum-assisted biopsy. Radiology 1997 , 204:485-488.

27. Helvie MA, Hessler C, Frank TS, Ikeda DM: Atypical hyperplasia of the breast: mammographic appearance and histologic correlation. Radiology 1991, 179:759-764.

28. Stomper PC, Cholewinski SP, Penetrante RB, Harlos JP, Tsangaris TN Atypical hyperplasia: frequency and mammographic and pathologic relationships in excisional biopsies guided with mammography and clinical examination. Radiology 1993, | 899:667-67|.

29. Dershaw DD, Abramson A, Kinne DW: Ductal carcinoma in situ: mammographic findings and clinical implications. Radiology 1989, 170:4II-4I5.

30. Slanetz PJ, Giardino AA, Oyama T, Koerner FC, Halpern EF, Moore $\mathrm{RH}$, Kopans DB: Mammographic appearance of ductal carcinoma in situ does not reliably predict histologic subtype. The breast journal 200I, 7:4I7-42I.

3I. Holland R, Hendriks JH: Microcalcifications associated with ductal carcinoma in situ: mammographic-pathologic correlation. Seminars in diagnostic pathology 1994, I I:181-192.

Publish with Bio Med Central and every scientist can read your work free of charge

"BioMed Central will be the most significant development for disseminating the results of biomedical research in our lifetime. "

Sir Paul Nurse, Cancer Research UK

Your research papers will be:

- available free of charge to the entire biomedical community

- peer reviewed and published immediately upon acceptance

- cited in PubMed and archived on PubMed Central

- yours - you keep the copyright 